Rosana Amora Ascari ${ }^{1}$

Daniela Fernanda Comiran²

Aila Anne Pinto Farias ${ }^{3}$

Larissa Evangelista Ferreira Correio ${ }^{4}$

resumo

O objetivo deste estudo foi analisar a percepção de idosos acerca da relação entre atividades sociais e saúde. É uma pesquisa exploratória, descritiva e com abordagem qualitativa realizada no segundo semestre de 2011 com 20 idosos, participantes e não participantes de atividades sociais, por meio de entrevista semiestruturada e anali-

1 Graduada em Enfermagem. Doutoranda em Enfermagem pela Universidade Federal do Rio Grande do Sul (UFRGS). Professora Assistente da Universidade do Estado de Santa Catarina (UDESC) vinculada ao Departamento de Enfermagem. E-mail: rosana.ascari@udesc.br

2 Graduada em Filosofia. Mestre em Ciências Ambientais. Mestranda em Educação pela Universidade Federal da Fronteira Sul (UFFS). Coordenadora Pedagógica do Serviço Nacional da Aprendizagem Industrial (SENAI/SC). E-mail: danielacomiran@gmail.com

3 Graduada em Enfermagem pela Universidade do Estado de Santa Catarina (UDESC). Mestranda em Saúde e Meio Ambiente pela Universidade do Vale de Joinville (UNIVILLE). E mail: ailaanne@ hotmail.com

4 Graduada em Enfermagem pela Universidade do Estado de Santa Catarina (UDESC). Especialista em Enfermagem do Trabalho pelo Centro Sul Brasileiro de Pesquisa, Extensão e Pós-Graduação (CENSUPEG). E-mail: larih.sa@hotmail.com 
sada pela técnica de análise de conteúdo. Desta análise, emergiram quatro categorias, que são: saúde e qualidade de vida, doença, ser saudável e ativo e limitações impostas pela terceira idade, as quais revelaram as percepções desses idosos acerca da relação entre atividades sociais e a saúde do idoso. Promover o envelhecimento ativo é uma das formas de preparar a sociedade para atender às necessidades da progressiva demanda de idosos.

palavras-chave

Saúde do Idoso. Participação Social. Enfermagem em Saúde Comunitária. Envelhecimento. Qualidade de Vida.

Introdução

Em todo o mundo, o contingente de pessoas com idade igual ou superior a sessenta anos tem crescido rapidamente. Segundo dados do Instituto Brasileiro de Geografia e Estatísticas (IBGE, 2012) no final do século passado, eram estimados 590 milhões de indivíduos nessa faixa etária, sendo projetada para 2025 a quantidade de um bilhão e duzentos milhões de idosos a partir dos sessenta anos e atingindo a marca de dois bilhões em 2050. As consequências do crescente número de idosos implicam no aumento das demandas sociais e passam a representar um grande desafio político, social e econômico.

No Brasil e nos demais países em desenvolvimento, é considerado idoso aquele que possui 60 anos ou mais de idade, de acordo com as leis 8842/94 (BRASIL, 1994) e 10741/03 (BRASIL, 2003), seguindo os padrões da Organização Mundial de Saúde (OMS).

Diante dessa realidade, faz-se necessário realizar um estudo mais profundo sobre os aspectos culturais, concepções e valores sociais em relação ao processo de envelhecimento.

O aumento considerável da população idosa em relação à faixa etária jovem pode ser explicado pela diminuição da mortalidade e da fecundidade, bem como pelo desenvolvimento tecnológico e urbano, que tem proporcionado maior esperança de vida aos indivíduos.

Entretanto, ainda é possível encontrar, no convívio dos grupos, pessoas com mais de 60 anos independentes e com todo o potencial para realizarem suas atividades diárias normais. Para isso, é importante que elas tenham 
qualidade de vida e recebam apoio da comunidade e da família, o que pode ser alcançado com a contribuição do setor da saúde.

Foi aprovada, em 1996, a Política Nacional de Saúde da Pessoa Idosa (BRASIL, 2006). Esta proposta defende que as práticas de saúde devem propiciar a manutenção das tarefas diárias da pessoa idosa, buscando a autonomia e a independência. A política delineia que o principal problema que tende a afetar a pessoa idosa, como consequência da evolução das suas enfermidades e do seu estilo de vida, é a perda de sua capacidade funcional. A perda das habilidades físicas e mentais necessárias à realização das atividades básicas e instrumentais da vida diária acaba por favorecer sentimentos de incapacidade e impotência, podendo acarretar em transtornos de diversas ordens, inclusive afetando a saúde mental. Assim, a equipe de saúde, ao desenvolver as ações de promoção da saúde, bem como de educação em saúde, pode contribuir para que a longevidade alcançada no decorrer desses últimos anos possa ser acompanhada pela qualidade de vida.

Esta pesquisa busca demonstrar quais as influências do envelhecimento ativo para a vida do idoso. Para tanto, foi realizada uma pesquisa no município de Chapecó, Santa Catarina em 2011, buscando compreender as concepções que cada idoso, participante ou não de atividades sociais, tem sobre a sua saúde.

\section{Método}

Esta é uma pesquisa exploratória, descritiva, com abordagem qualitativa e desenvolvida no segundo semestre de 2011. Participaram do estudo 20 idosos, com 60 anos ou mais, sendo dez (10) participantes de atividades sociais e dez (10) não participantes de atividades sociais, todos residentes em Chapecó, município da Região Oeste de Santa Catarina, indicados aleatoriamente pela Unidade Básica de Saúde (UBS).

Para a coleta de dados, utilizou-se a entrevista com roteiro semiestruturado, a qual fora realizada nos domicílios e acompanhadas pelos Agentes Comunitários de Saúde (ACS) vinculados à UBS. Para classificar os idosos em participantes e não participantes de atividades comunitárias, os pesquisadores questionavam os idosos quanto à participação ou não em atividades comunitárias voltadas aos idosos.

As entrevistas foram gravadas e transcritas na íntegra para análise posterior dos dados utilizando-se a técnica de análise de conteúdo proposta por Minayo (2004). Desta análise, emergiram quatro categorias, que são: saúde e qualidade de vida, doença, ser saudável e ativo e limitações impostas pela terceira 
idade, as quais revelaram as percepções desses idosos acerca da relação entre atividades sociais e a saúde do idoso.

Os aspectos éticos foram seguidos conforme a Resolução 196/96 do Conselho Nacional de Saúde. O projeto foi aprovado pelo Comitê de Ética em Pesquisa da UDESC sob o parecer no 127/2011. Todos os participantes assinaram o Termo de Consentimento Livre e Esclarecido, e foram esclarecidos sobre o anonimato e garantidos o direito de retirar-se da pesquisa a qualquer momento se assim desejassem.

\section{Resultados e discussões}

Participaram da pesquisa 20 idosos acima de 60 anos, sendo 13 do sexo feminino e sete do masculino. A média de idade dos idosos ficou em 71,8 anos de idade para as mulheres e 71,5 anos para os homens.

Quanto à escolaridade, $95 \%$ dos idosos concluíram o ensino primário (n $=19)$ e apenas $5 \%$ dos idosos concluiu o ensino médio $(n=1)$.

A religião católica predominou em $90 \%$ dos idosos, o que se deve ao fato do município ter sido colonizado, em grande, parte por europeus e a religião católica ser de origem europeia. Apenas 10\% dos idosos pertencem à religião evangélica.

Ainda sobre os reflexos de uma colonização alemã, italiana e polonesa, os idosos, em sua maioria, passaram boa parte de suas vidas "trabalhando na colônia", como eles mesmos se referem ao trabalho na agricultura que predominava antigamente em virtude do pouco acesso da população ao estudo e da maioria da população residir em área rural. Cerca de $45 \%$ dos idosos trabalhavam como agricultores, $5 \%$ como pensionista, $10 \%$ como caixa de farmácia ou mercado e $5 \%$ como caminhoneiro. $10 \%$ por cento dos idosos eram vendedores, $10 \%$ eram trabalhadores de empresas e $15 \%$ trabalhavam como domésticas.

Todos os idosos já encerraram suas carreiras profissionais e recebem ajuda de custo do Governo como o Auxílio-doença ou o Benefício Assistencial ao Idoso, aposentadoria do esposo para aquelas que são viúvas e aposentadoria para os idosos do sexo masculino que encerraram algum tipo de carreira profissional.

Neste contexto, $55 \%$ dos idosos recebem, por mês, o valor de 1 salário mínimo, 35\% recebem renda, por mês, de 1,1 a 2 salários mínimos, $5 \%$ recebem de 2,1 a 5 salários mínimos por mês e $5 \%$ recebem renda superior a 5 salários mínimos por mês.

O grupo participante de atividades sociais possui renda média de dois salários mínimos, o que é superior ao grupo de idosos não participantes de atividades, que possui renda média de um salário e meio. 
Entretanto, idosos que não participam das atividades sociais não consideram a condição econômica como fator limitante para a sua integração com a comunidade. Nota-se, também, que nenhum idoso ficou desamparado financeiramente após atingir a terceira idade, o que é provavelmente justificado pela previdência social e pelo direito trabalhista. Todos os idosos recebem seus benefícios constatando que, no âmbito financeiro, as leis são aplicadas corretamente neste grupo analisado:

\begin{abstract}
Aos idosos, a partir de 65 (sessenta e cinco) anos, que não possuam meios para prover sua subsistência, nem de tê-la provida por sua família, é assegurado o benefício mensal de 1 (um) salário-mínimo, nos termos da Lei Orgânica da Assistência Social - LOAS (BRASIL, 2003).
\end{abstract}

Em relação aos grupos familiares, $40 \%$ moram com seus respectivos cônjuges, $25 \%$ dos idosos moram sozinhos, $35 \%$ moram com um ou mais filhos. Não existe diferença significativa entre os idosos participantes de atividades sociais e os idosos não participantes em relação ao grupo familiar.

Dos idosos participantes de atividades sociais, 7 são do sexo feminino, recorrem mais à Unidade Básica de Saúde e participam mais de atividades com a comunidade, quando comparadas aos homens. Os indivíduos do sexo masculino mantêm-se mais afastados da comunidade no que se refere a atividades preventivas e procuram muito menos a UBS, com o intuito de buscar orientação e educação em saúde.

Este fato pode ser comprovado por vários autores como Favorito (2008); Courtenay (2000) ${ }^{6}$; Laurenti, Jorge e Gotlieb (2005) ; e Luck, Bamford e Williamson $(2000)^{8}$ apud Brasil (2008), os quais apontam que vários estudos comparativos entre homens e mulheres têm comprovado o fato de que os homens são mais vulneráveis às doenças, sobretudo às enfermidades graves e crônicas, e que morrem mais precocemente do que as mulheres:

5 FAVORITO, Luciano A. Epidemiologic study on penile cancer in Brazil. International Brazilian Journal of Urology, Rio de Janeiro, v. 34, n. 5, p. 587-593, set./out. 2008. Apud BRASIL, 2008.

6 COURTENAY, Will H. Constructions of masculinity and their influence on men's well-being: a theory of gender and health. Social Science and Medicine, New York, v. 50, n. 10, p. 1385-1401, May 2000. Apud BRASIL, 2008.

7 LAURENTI, Ruy; JORGE, Maria Helena Prado de Mello; GOTLIEB, Sabrina Léa Davidson. Perfil epidemiológico da morbi-mortalidade masculina. Ciência \& Saúde Coletiva, Rio de Janeiro, v. 10, n. 1, p. 35-46, jan./mar. 2005. Apud BRASIL, 2008.

8 LUCK, Mike; BAMFORD, Margaret; WILLIAMSON, Peter. Men's health: perspectives, diversity and paradox. Oxford: Blackwell Science, 2000. Apud BRASIL, 2008. 


\begin{abstract}
A despeito da maior vulnerabilidade e das altas taxas de morbimortalidade, os homens não buscam, como o fazem as mulheres, os serviços de atenção primária [...] adentrando o sistema de saúde pela atenção ambulatorial e hospitalar de média e alta complexidade, o que tem como conseqüência agravo da morbidade pelo retardamento na atenção e maior custo para o sistema de saúde (BRASIL, 2008).
\end{abstract}

A resistência masculina à atenção primária aumenta não somente a sobrecarga financeira da sociedade, mas, também, o sofrimento físico e emocional do paciente e de sua família na luta pela conservação da saúde e da qualidade de vida dessas pessoas. Para Keijzer (2003) ${ }^{9}$; Schraiber, Gomes e Couto (2005) ${ }^{10}$; e Sabo (2002) $)^{11}$ apud Brasil (2008), a doença é considerada como um sinal de fragilidade que os homens não reconhecem como inerente à sua própria condição biológica. O homem julga-se invulnerável, o que acaba por contribuir para que ele cuide menos de si mesmo e se exponha mais às situações de risco.

Dos idosos não participantes de atividades sociais, 6 eram do sexo feminino e 4 do sexo masculino. Estima-se que o número de mulheres não participantes de atividades sociais, superior ao número de homens, se deva ao fato das mulheres possuírem maior disponibilidade e interesse em participar das entrevistas.

Após a realização da leitura exploratória atenta das transcrições das entrevistas, buscou-se pontos divergentes e convergentes nas falas de cada participante. Dessa análise, emergiram quatro categorias, que são: saúde e qualidade de vida, doença, ser saudável e ativo e limitações impostas pela terceira idade, as quais revelaram as percepções desses idosos acerca da relação entre atividades sociais e a saúde do idoso.

\title{
3.1 Saúde e qualidade de vida
}

Em geral, 60\% dos idosos entendem que saúde é uma coisa boa, a coisa mais linda do mundo e essencial para sobrevivência e felicidade, como exposto nos relatos:

\footnotetext{
9 KElJZER, Benno de. Hasta donde el cuerpo aguante: género, cuerpo y salud masculina. In: CÁCERES, Carlos Fernando (Coord.). La salud como derecho ciudadano: perspectivas y propuestas desde América Latina. Lima: Universidad Peruana Cayetano Heredia, 2003. p. 137-52. Apud BRASIL, 2008.

10 SCHRAIBER, Lília Blima; GOMES, Romeu; COUTO, Márcia Thereza. Homens e saúde na pauta da saúde coletiva. Ciência \& Saúde Coletiva, Rio de Janeiro, v. 10, n. 1, p. 7-17, jan./mar. 2005. Apud BRASIL, 2008.

11 SABO, Donald. O estudo crítico das masculinidades. In: ADELMAN, Mirian; SILVESTRIN; Celsi B. Gênero Plural: um debate interdisciplinar. Curitiba: Editora UFPR, 2002. p. 33-46. Apud BRASIL, 2008.
} 


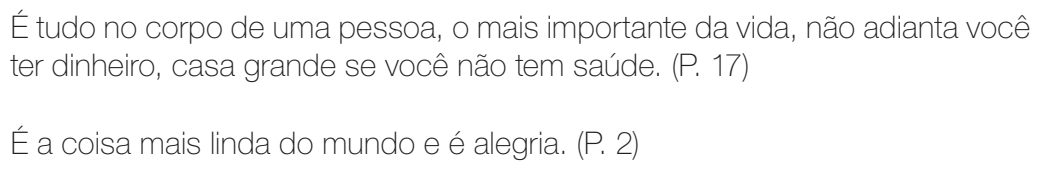

Para 40\% dos idosos, a saúde está relacionada a diversos aspectos como estilo de vida, acesso e carências do Sistema Único de Saúde (SUS).

Em relação aos participantes de atividades sociais, 30\% entendem que a saúde é o mais importante na vida, fato este também evidenciado na categoria dos não participantes de atividades sociais, em que $30 \%$ consideram a saúde como fundamental para vida.

Dos idosos participantes de atividades sociais, $15 \%$ relacionaram saúde ao fato de participarem das atividades com a comunidade, levando ao entendimento de que para os idosos que possuem uma vida mais ativa, eles acabam criando o hábito de participar de atividades sociais e entendem que a saúde é justamente manter-se ativo:

Saúde para mim é saber se alimentar, ter uma vida social, fazer exercícios físicos, a pessoa da nossa idade não pode parar! (P. 9)

Na categoria dos não participantes de atividades sociais, 15\% dos idosos relacionaram saúde ao fato da pessoa fazer por merecer, se cuidar e prevenir doenças:

Saúde para mim é se manter sempre se consultando, vendo a pressão, esse tipo de coisa, né? (P. 8)

Para mim, saúde é comer bem e dormir bem. (P. 11)

Por fim, $5 \%$ dos participantes de atividades sociais relacionaram a saúde ao fato de realizar tratamento médico e ter acesso ao sistema de saúde de alta complexidade:

Para mim, saúde [...] precisa ter remédios e tratamento especial para todo mundo. (P. 11)

No grupo dos não participantes de atividades sociais, $5 \%$ relacionaram a saúde às fragilidades e carências no atendimento do Sistema Único de Saúde (SUS):

Saúde, para mim, é um atendimento péssimo, porque você vai no postinho e fica horas esperando para ser atendido. Acho que deveria ter uma fila só para os idosos, deveria ter médico separado dos outros só para os aposentados. (P. 3) 
Nota-se que as concepções de saúde mantêm um padrão entre os grupos participantes e não participantes de atividades sociais. Entretanto, na categoria dos participantes de atividades sociais, $15 \%$ dos idosos relacionam a saúde justamente ao fato de possuírem uma vida ativa, mostrando que, para eles, a saúde significa conversar, praticar esportes e cuidar da alimentação, caracterizando um grupo de pessoas que buscam orientação sobre qualidade de vida e que participam do grupo de idosos da comunidade que dispõe de palestras e atividades educativas que possuem a finalidade de nortear os idosos em busca de um envelhecimento saudável e ativo.

Nesta mesma proporção, $15 \%$ dos idosos que não participam de atividades sociais atribuíram a saúde ao fato da pessoa se cuidar, o que leva a um envelhecimento saudável. Contudo, em nenhum momento citaram o convívio com a sociedade, as conversas com amigos, as práticas de atividades físicas ou cuidados específicos com alimentação, o que caracteriza um grupo carente de informações e que buscam o isolamento social. Ainda, enfatizaram o péssimo atendimento do SUS na procura por medicamentos e consultas médicas.

\section{Saúde para idosos é um conceito multidimensional, pois depende da situação socioeconômica, da rede social de apoio, da condição de saúde (destacando-se a saúde mental) e do acesso e uso de serviços de saúde. (LIMA-COSTA, 2007, p. $1893^{12}$ apud FERRETTI; NIEROTKA; SILVA, 2009).}

Ao identificar o que os idosos entendem sobre a saúde, eles foram questionados sobre suas concepções em relação à doença.

\subsection{A doença}

Em relação à compreensão sobre a doença, 55\% dos idosos relacionam a doença a uma coisa muito ruim, desgosto, preocupação, tristeza e desânimo. Outros $10 \%$ relacionam a doença ao estilo de vida que cada um procura para si, mostrando consciência sobre a importância do autocuidado para obter uma vida saudável. Para $25 \%$, as doenças estavam relacionadas às experiências pessoais e doenças de familiares. Um idoso relacionou sua concepção sobre doença à ascensão do câncer, e outro idoso relacionou doença aos desgostos e conflitos familiares.

12 LIMA-COSTA, Maria Fernanda et al. A influência de respondente substituto na percepção da saúde de idosos: um estudo baseado na Pesquisa Nacional por Amostra de Domicílios $(1998,2003)$ e na coorte de Bambuí, Minas Gerais, Brasil. Cadernos de Saúde Pública, Rio de Janeiro, v. 23, n. 8, p. 1893-1902, ago. 2007. Apud FERRETTI; NIEROTKA; SILVA, 2009. 
Dentro da categoria dos participantes de atividades sociais, $20 \%$ se referiam à doença como "uma coisa ruim", "um transtorno", "preocupação", "desânimo", "estrago" e "tristeza". Não existindo um conceito comum a todos sobre o termo doença, todos se referem à mesma descrevendo suas consequências.

Não diferindo, 35\% dos idosos não participantes de atividades sociais também classificaram a doença como uma coisa ruim, que consequentemente se reflete em tristeza e luta.

Na categoria dos participantes de atividades sociais, $10 \%$ relacionam a doença com suas experiências previamente vivenciadas:

Eu penso em ficar bom, é uma coisa muito ruim porque eu tive um derrame há 17 anos atrás e já sofri muito. (P. 5)

15\% dos não participantes de atividades sociais mantiveram a mesma ideia:

É pressão alta e problema na tireoide que eu tenho. (P. 6)

Eu já tive prostatite crônica, por isso eu vivo com Auxílio-doença. Foi uma experiência muito ruim. (P. 11)

Para 5\% da categoria de participantes de atividades sociais, a doença está relacionada com desgostos e conflitos familiares:

A doença é desgosto com os familiares, muitas vezes causada por filhos e pela família! (P. 9)

Por fim, 10\% dos idosos que participam das atividades sociais relacionam doença ao estilo de vida e comportamento de cada um:

A doença é uma coisa que depende de cada um. Se eu não me cuidar, fico doente né! (P. 13)

Nota-se que a visão dos idosos participantes e não participantes de atividades sociais são muito semelhantes visto que a maioria apontou que a doença é uma experiência ruim, mas no grupo dos participantes de atividades sociais, a concepção sobre doença foi mais fragmentada, sendo 10\% em razão de experiências já vividas, $10 \%$ decorrente do estilo de vida e $5 \%$ relacionou doença aos conflitos familiares, confirmando que os relacionamentos familiares são determinantes para uma boa condição de saúde, principalmente após a terceira idade, em que as relações sociais tendem a se estreitar. Deve-se levar em consideração que as necessidades de atenção e cuidados aumentam, e a 
negligencia familiar pode levar ao desenvolvimento de patologias por parte dos idosos, principalmente as de caráter psicoemocional.

Na categoria dos não participantes, esta fragmentação não foi observada, sendo que, para eles, a doença significa basicamente uma coisa ruim e tristeza. Nesta categoria, a doença também foi relacionada com experiências vividas.

\subsection{Ser saudável e ativo}

Quando questionado aos idosos se eles se consideram saudáveis e ativos, 90\% dos idosos responderam que sim e, apesar de algumas intercorrências, sentem-se saudáveis e ativos. $5 \%$ se consideram parcialmente saudáveis e ativos e outros $5 \%$ responderam que se sentem mais ou menos saudáveis e ativos.

Na categoria dos participantes de atividades sociais, $45 \%$ se consideram saudáveis e ativos, sendo que todos frequentam o grupo de idosos e ocupam seu tempo livre, quando não estão nas atividades comunitárias, e realizam afazeres domésticos e atividades laborais como crochê e tricô, como verificamos no relato:

Sim, eu faço todo serviço de casa! (P. 4)

Na mesma proporção, $45 \%$ dos idosos não participantes de atividades sociais relatam que apesar de alguns problemas crônicos de saúde, ainda se sentem saudáveis e ativos:

Sim, faço tudo ainda, apesar de ter osteoporose, faço tudo! (P. 3)

Para 5\% dos idosos participantes de atividades sociais, mesmo acamados, eles afirmam que é possível realizar algum serviço doméstico:

Sim, me sinto bem mas ultimamente tenho que ficar na cama, pois tenho desgaste ósseo. (P. 5)

No grupo dos não participantes de atividades sociais, $5 \%$ responderam que, em decorrência de seus últimos exames e problemas de saúde, consideram-se mais ou menos ativos em razão de algumas restrições médicas:

Eu me sinto mais ou menos, eu tenho tido alguns problemas de saúde, passei por vários exames e, durante os exames, eu sofri um infarto e, depois disso, fiquei na UTI. Foi um trauma. (P. 15) 
O que difere os grupos é o fato dos idosos participantes de atividades com a comunidade utilizarem sua saúde e seu estado ativo para compartilhar de atividades educativas e em grupo com a sociedade, sendo que esta mesma afirmação não pode ser atribuída aos idosos não participantes de atividades sociais. Os últimos, apesar de, em sua maioria, se considerarem saudáveis e ativos, não compartilham de momentos educativos e de lazer com a comunidade, utilizando suas boas condições de saúde para realizar trabalhos em casa de caráter doméstico. Para alguns idosos, o fato de não buscar atividades sociais não está relacionado com a falta de saúde, e sim a ausência de estímulo e interesse próprio visto que, durante as entrevistas, os mesmos relatam não buscar uma vida ativa por falta de interesse.

A pobreza de relações sociais, como um fator de risco à saúde, tem sido considerada tão danosa quanto o fumo, a pressão arterial elevada, a obesidade e a ausência de atividades físicas (ANDRADE; VAITSMAN, 2002 apud CARNEIRO et al., 2007) ${ }^{13}$.

Para Ramos (2002) apud Carneiro et al. (2007) $)^{14}$, esse conjunto de evidências sugere que a deterioração da saúde pode ser causada não somente por um desgaste natural do organismo, pelo sedentarismo ou pelo uso do tabaco, mas, também, pela redução da quantidade ou qualidade das relações sociais, em que a falta de estímulo se torna um fator agravante para a promoção do envelhecimento ativo.

Pode-se observar, também, que mesmo se considerando saudáveis e ativos, os idosos possuem uma ou mais doença crônica e, dentre elas, as mais prevalentes são a hipertensão arterial e diabetes. Os descendentes de povos europeus mantêm uma alimentação que envolve muitas carnes gordas. Consequentemente, a prevalência dessas doenças pode ser considerada previsível.

As populações que se deslocam (ou foram deslocadas) trazem, com elas, seus hábitos, costumes e necessidades alimentares, enfim, todo um conjunto de práticas ligadas àquilo que o Pierre Bourdieu denomina de habitu. (SETTON, 2002):

Esse tipo de culinária vai estar ancorado nas características apresentadas ainda hoje pela culinária de origem alemã, cuja cozinha embora se diferencie segundo as regiões, caracteriza-se em geral por pratos fortes, substanciosos, ricos em gorduras e molhos grossos e por uma confeitaria refinada, que consiste em um dos seus itens mais importantes (LEAL, 1998, p. $107^{15}$ apud SILVA, 2007).

13 ANDRADE, Gabriela R. B. de; VAITSMAN, Jeni. Apoio social e redes: conectando solidariedade e saúde. Ciência \& Saúde Coletiva, v. 7, n. 4, p. 925-934, 2002. Apud CARNEIRO et al., 2007.

14 RAMOS, Marília P. Apoio social e saúde entre idosos. Sociologias, Porto Alegre, v. 4, n. 7, p. 156 175, jan./jun. 2002. Apud CARNEIRO et al., 2007.

15 LEAL, Maria Leonor de Macedo Soares. A História da Gastronomia. Rio de Janeiro: Editora Senac Nacional, 1998. Apud SILVA, 2007. 
As particularidades culturais mostram-se como fator predisponente ao desenvolvimento de certas patologias, fazendo-se necessário disponibilizar programas de orientação e recursos que ofereçam meios de adaptação para a população buscar um envelhecimento saudável e sem limitações.

Após identificar as percepções dos idosos em relação a sua saúde e doença, indagou-se quais os fatores que os mesmos consideram importantes para se obter uma boa saúde e viver com qualidade.

Em geral, na percepção dos idosos, para obter boa saúde, é necessário buscar uma boa qualidade de vida, priorizando alimentação adequada, rica em frutas e verduras, prática regular de exercícios físicos, evitando o consumo de álcool e tabaco, ou seja, evitar vícios, bem como ocupar o tempo com atividades lúdicas, fazer regimes no sentido de controlar a quantidade de alimentos ingeridos e tomar a medicação corretamente, o que se confirma em Scherer et al. (2007) apud Ferreti, Nierotka e Silva (2009) ${ }^{16}$.

$\mathrm{Na}$ categoria dos participantes de atividades sociais, $40 \%$ idosos entrevistados responderam que, para obter boa saúde, é necessário viver com qualidade, priorizar os cuidados com a alimentação, praticar exercícios físicos, não se estressar, buscar atividades de lazer como dança, ter amigos, não alimentar vícios, realizar atividades lúdicas e tomar a medicação corretamente:

Se cuidar, evitar depressão, mas nunca fazemos isso aqui. Comemos tudo colonial, tudo com gordura. É assim que gostamos. Não devemos ficar só na cama, eu tomo remédios para depressão! (P. 3)

O cuidado com o espírito, e a felicidade foram apontados como fatores fundamentais na obtenção de saúde:

Para ter saúde, tem que ser alegre, ter simplicidade, cuidar do espírito, tudo junto! (P. 13)

A prevenção como fator determinante para obtenção de saúde foi observada:

Tem que fazer prevenção. Eu acho que é o principal. Se cuidar, alimentação, exercícios, não dá para ficar parada! Tem que deixar a cabeça funcionar. (P. 18)

16 SCHERER, Magda Duarte dos Anjos et al. O viver saudável e o viver não saudável: o significado para mulheres maduras e ativas. Cadernos Saúde Coletiva, Rio de Janeiro, v. 15, n. 1, p. 131-146, jan./mar. 2007. Apud FERRETI; NIEROTKA; SILVA, 2009. 


\subsection{Limitações impostas pela terceira idade}

Na categoria dos não participantes de atividades sociais, $5 \%$ destacaram o cuidado com alimentação e prática de exercícios, embora tenham afirmado que o fato de ter uma idade avançada, que consequentemente leva ao abandono do trabalho e de algumas atividades cotidianas, é um fator que dificulta a obtenção de boa saúde.

Os dados acima vão do encontro com as afirmações de Camarano (1999)17 apud Oliveira, Gomes e Oliveira (2006), em que o autor descreve que todas as doenças são psicossomáticas e iniciam como doenças emocionais e se transformam em doenças físicas e reais, como é o caso da depressão. A depressão no idoso geralmente ocorre após ele adquirir patologias como câncer, mal de Parkinson, demência e diabetes, junto a perdas de pessoas queridas, morte dos amigos, familiares e cônjuge, o fim de vida profissional e da fase reprodutiva, e a diminuição de renda e do poder econômico:

Saúde é tudo porque, com saúde, você faz tudo, você vive, e, sem saúde, você acaba ficando em casa, né?! Não ser triste, cuidar da alimentação, dormir bem. A idade tira a saúde porque agora, com a idade, a gente deixa de trabalhar e de fazer as coisas. (P. 15)

Evidencia-se a existência de um senso comum entre as categorias visto que a maioria dos entrevistados reconhece que, para a obtenção de boa saúde, faz-se necessário não só viver, mas viver com qualidade. Destacaram a importância da alimentação, do convívio com a sociedade e da prática de exercícios físicos como fatores potenciais nessa busca. Na categoria de participantes de atividades sociais, $40 \%$ dos entrevistados mantiveram esse padrão de respostas, sendo que a mesma proporção pode ser observada nos idosos não participantes de atividades sociais, em que $40 \%$ dos entrevistados não apontaram nenhuma diferença significativa em relação às respostas do outro grupo.

Os participantes de atividades sociais conseguiram formular respostas mais completas, incluindo a importância dos amigos, do convívio com a sociedade e dos benefícios das atividades lúdicas, fator este que não foi evidenciado na categoria dos não participantes. Os idosos do grupo não participante de atividades sociais buscaram enfatizar a prevenção de doenças como a depressão e justificar o progressivo isolamento social em razão das limitações causadas

17 CAMARANO, Ana Amélia. Considerações finais. In: idosos brasileiros. Rio de Janeiro: IPEA, 1999. p. 369-382. (Org.). Muito além dos 60: os novos 
pela idade avançada, as quais que levaram ao abandono do trabalho e à acomodação, diminuindo o interesse em manter um convívio social.

Oliveira, Gomes e Oliveira (2006) elencaram que diversos estudos realizados em comunidades evidenciam correlação positiva entre a idade acima de 65 anos e a presença de sintomas depressivos e descrevem dois estudos em que o percentual variou de 14,7 e 15\% entre portadores de sintomas depressivos.

Um estudo realizado em idosos atletas em Florianópolis, Santa Catarina sinalizou que a prática regular de exercícios físicos é uma característica dos idosos participantes do estudo, o que parece contribuir para um estilo de vida mais saudável (MEURER et al., 2013).

A predisposição do desenvolvimento de depressão na terceira idade apresenta-se como característica não só no município de Chapecó. Nota-se que mesmo os idosos que vivem e socializam-se com a comunidade podem, em algum momento, apresentar características depressivas visto que, paralelamente ao abandono do trabalho, à perda do cônjuge e ao afastamento dos filhos, também ocorrem alterações fisiológicas a nível hormonal que geram essa maior predisposição.

A depressão na velhice foi proposta como sendo, por hipótese, o que mais contribui socialmente para a doença crônica.

Diante das evidencias, torna-se necessário promover saúde não apenas no âmbito físico, em que comumente se expressam as patologias, mas deve-se também atentar para a saúde psicoemocional, a qual, quando não satisfatória, pode vir a desenvolver ou agravar as patologias.

\section{Considerações finais}

As concepções dos idosos participantes e não participantes de atividades sociais sobre saúde e doença não apontaram diferenças de grande significância, embora os idosos que buscam viver ativamente soubessem contextualizar melhor as respostas e conseguissem verbalizar o que deve ser priorizado para viver de forma saudável. Os idosos que, por falta de interesse, não buscam viver ativamente apenas verbalizaram que é necessário viver com qualidade, mas não souberam elaborar respostas argumentativas como ocorreu no grupo anterior.

A renda mensal dos participantes de atividades sociais é superior à renda dos não participantes, sendo que os idosos não participantes de atividades sociais relataram que a falta de dinheiro dificulta sua participação. Em contrapartida, os idosos que participam das atividades relataram que a renda não 
influencia uma vez que a maioria das atividades é gratuita e basta ter interesse e força de vontade para participar.

Da mesma forma, os idosos que participam de atividades sociais que responderam se sentir felizes é expressivamente maior do que o número de idosos que não participam de atividades comunitárias. Todos os idosos atribuíram suas condições de felicidade ou de tristeza diretamente aos seus relacionamentos familiares, mostrando que, nessa etapa da vida, a família ganha maior valor e significado para o idoso.

Todos os idosos que sentiram falta do passado, de alguma forma, mencionaram parentes já falecidos, incluindo pais e mães, mas principalmente os cônjuges e irmãos, explicitando o valor da família para esse grupo de idosos, fato este que se confirma com as literaturas e os estudos sobre o envelhecimento.

Compreender a percepção do idoso sobre as atividades sociais e saúde representa hoje uma necessidade imediata para os profissionais da enfermagem uma vez que, nessa fase da vida, a busca pelos serviços de saúde se acentua e, muitas vezes, as doenças não são visíveis fisicamente. Contudo, podem ser minimizadas com a participação ativa dos idosos em seu ambiente familiar e social.

Talvez seja mesmo complicado mudar a concepção de toda sociedade, mas cada um dentro de suas comunidades, cuidando e respeitando seus idosos, podem começar a fazer diferença. O envelhecimento e suas consequências físicas são inevitáveis, mas é possível e desejável eliminar o preconceito, desfazer estereótipos e ampliar a autonomia e o espaço de participação do idoso como um ser humano com direitos, deveres, conquistas e superações, alguém capaz de amar e ser amado, trabalhar, contribuir, ter ideias, gerar renda, ensinar e, por que não, aprender.

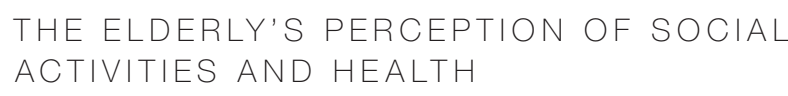

The aim of this study was to analyze the perception of the elderly in the relationship between social activities and health. It is an exploratory and descriptive qualitative approach, performed in the second half of 2011 with 20 elderly participants and non-participants in social activities through semi-structured interviews analyzed by content analysis technique. From this analysis, four categories emerged, which are: health and quality of life, disease, being healthy and active and limitations imposed by the advanced age, which revealed the 
perceptions of the elderly on the relationship between social activities and health of the elderly. To promote active aging is one of the ways to prepare society to know the needs of progressive demand for seniors.

\title{
keywords
}

Health of the Elderly. Social Participation. Community Health Nursing. Aging. Quality of Life.

\author{
referências
}

BRASIL. Ministério da Saúde. Secretaria de Atenção à Saúde. Departamento de Ações Programáticas Estratégicas. Política Nacional de Atenção Integral à Saúde do Homem (Princípios e Diretrizes). Brasília, DF, 2008. Disponível em: <http://dtr2001.saude.gov. br/sas/PORTARIAS/Port2008/PT-09-CONS.pdf>. Acesso em: 8 out. 2013.

Ministério da Saúde. Portaria n. 2.528, de 19 de outubro de 2006. Aprova a Política Nacional de Saúde da pessoa ldosa. Brasilia, DF, 2006. Disponível em: <http://dtr2001. saude.gov.br/sas/PORTARIAS/Port2006/GM/GM-2528.htm>. Acesso em: 15 jul. 2013.

Lei n. 8.842, de 4 de janeiro de 1994. Dispõe sobre o Estatuto do Idoso, cria Conselho Nacional do Idoso e dá outras providências. Diário Oficial [da] República Federativa do Brasil, Brasília, DF, 4 jan. 1994. Disponível em: <http://www.jusbrasil.com. br/topicos/11737936/lei-n-8842-de-04-de-janeiro-de-1994>. Acesso em: 11 jun. 2013

. Lei 10.741 de $1^{\circ}$ de outubro de 2003. Dispõe sobre o Estatuto do Idoso e dá outras providências. Diário Oficial [da] República Federativa do Brasil, Brasília, DF, 1 out. 2003. Disponível em: <http://www.planalto.gov.br/ccivil_03/leis/2003/10.741. htm>. Acesso em: 16 jun. 2013

CARNEIRO, Rachel Shimba et al. Qualidade de vida, apoio social e depressão em idosos: relação com habilidades sociais. Psicologia: Reflexão e Crítica, Porto Alegre v. 20, n. 2, p. 229-37, 2007. Disponível em: <http://www.scielo.br/pdf/prc/v20n2/ a08v20n2.pdf>. Acesso em: 20 ago. 2013

FERRETTI, Fátima; NIEROTKA, Rosana Paula; SILVA, Márcia Regina da. Concepção de saúde segundo relato de idosos residentes em ambiente urbano. Interface: Comunicação, Saúde, Educação, Botucatu, v. 15, n. 37, p. 565-572, abr./jun. 2011. Disponível em: <http://www.scielo.br/pdf/icse/2011nahead/aop1211.pdf>. Acesso em: 20 out. 2012

INSTIUTO BRASILEIRO DE GEOGRAFIA E ESTATÍSTICA. Estimativas populacionais para os municípios brasileiros em 01.07.2012. Rio de Janeiro: IBGE, 2012. Disponíve em: <http://www.ibge.gov.br/home/estatistica/populacao/estimativa2012/>. Acesso em: 20 out. 2013.

MEURER, Simone Teresinha et al. Perfil do estilo de vida de idosos atletas. Estudos Interdisciplinares sobre o Envelhecimento, Porto Alegre, v. 18, n. 2, p. 401-409, dez. 2013 Disponivel em: <http://seer.ufrgs.br/index.php/RevEnvelhecer/article/view/30843/27665>. Acesso em: 11 jan. 2014

MINAYO, Maria Cecília de Souza. Pesquisa social: teoria, método e criatividade. 23 ed. Petrópolis: Vozes, 2004.

OLIVEIRA, Deise A. Almeida Pires; GOMES, Lucy; OLIVEIRA, Rodrigo F. Prevalence of depression among the elderly population who frequent community centers. Revista de Saúde Pública, São Paulo, v. 40, n. 4, p. 736-736, ago. 2006. Disponível em: <http:// www.scielo.br/pdf/rsp/v40n4/26.pdf>. Acesso em: 16 out. 2013. 
SETTON, Maia de Graça Jacintho. A teoria do habitus em Pierre Bourdieu: uma leitura contemporânea. Revista Brasileira de Educação, Rio de Janeiro, n. 20, p. 60-70, maio/ jun./jul./ago. 2002. Disponível em: <http://www.scielo.br/pdf/rbedu/n20/n20a05>. Acesso em: 24 jan. 2015 .

SILVA, Marilda Checcucci Gonçalves da. O impacto da alimentação europeia sobre a produção de alimento e a culinária do médio Vale do Itaiaí/SC. In: LIMA FILHO, Manuel Ferreira; ECKERT, Cornelia; BELTRÃO, Jane Felipe (Org.). Antropologia e patrimônio cultural: diálogos e desafios contemporâneos. Blumenau: Nova Letra, 2007. p. 101-132. Disponível em: <http://www.abant.org.br/conteudo/livros/PatrimonioCultural.pdf>. Acesso em: 24 jan. 2015. 